\title{
Publicações sonoras: entre processos de escuta e participação ${ }^{1}$
}

\section{Audio publications: between listening processes and participation}

\author{
Franciele Favero ${ }^{2}$ \\ Raquel Stolf ${ }^{3}$
}

Submetido em 11 de abril e aprovado em 13 de maio de 2019.

Resumo: O texto propõe reflexões sobre desdobramentos de publicações sonoras em instalações, proposições e ações sonoras, ou vice-versa, envolvendo diferentes processos de escuta, entre o infra-ordinário e o infra-mince, entre o lugar de escuta de espaços sonoros fronteiriços, o que pressupõe trânsitos entre contextos e falas atravessadas, pensando-se e praticando-se a escuta como situação, campo e espaço de participação. Deste modo, são investigados os projetos The Sonic Body: Figures 1-12 (2011), de Brandon LaBelle, Crackers (2001) de Christof Migone, Horizontal Radio (1995), proposta pela ONF, bem como os processos de construção dos projetos e das publicações Como falar entre fronteiras (2015), de Franciele Favero, Panquecas fantasmáticas e FORA [DO AR] (2004), de Raquel Stolf. Dialogando com estas reflexões, abordam-se relações com autores e autoras como José Iges, Walter Zanini, Brandon LaBelle, David Toop, Sabine Breitsameter e Gale Joseph-Hunter.

Palavras-Chave: Arte sonora. Publicação sonora. Processos de escuta. Participação.

Abstract: This text presents some reflections about artistic processes when audio publications generate installations, propositions and sound actions, or vice-versa, involving different processes of listening, between the infra-ordinary and the inframince, between a place of listening of border sound spaces, which presupposes transits between contexts and multiple speeches, thinking and practicing the listening as situation, field and space of participation. Thus, this text investigates projects, such as The Sonic Body: Figures 1-12 (2011), by Brandon LaBelle, Crackers (2001), by Christof Migone, and Horizontal Radio (1995), proposed by ONF, as well as the processes of construction of the projects and the publications Como falar entre fronteiras (2015), developed by Franciele Favero, Panquecas fantasmáticas and FORA [DO AR] (2004), proposed by Raquel Stolf. In connection with these reflections, it approaches other authors and writers, such as José Iges, Walter Zanini, Brandon LaBelle, David Toop, Sabine Breitsameter and Gale Joseph-Hunter.

Keywords: Sound art. Audio publication. Listening processes. Participation. 


\section{Antecedentes}

Um pressuposto para abordarmos alguns desdobramentos de publicações sonoras em instalações, proposições e ações sonoras, ou vice-versa, envolvendo diferentes processos de escuta e participação, consiste nos usos heterogêneos do som no campo das artes. Deste modo, algumas experiências foram cruciais para o desenvolvimento de reflexões acerca do uso da sonoridade nesse campo, envolvendo relações entre contextos e trajetórias desde as "experiências futuristas e dadaístas, passando por Duchamp, Cage e o grupo Fluxus, relacionando-se e intersectando-se com outras áreas, como a música experimental e a poesia sonora" (STOLF, 2011, p. 288). Em relação à contribuição do grupo Fluxus, Walter Zanini (2004, p. 16) aponta aspectos importantes a partir do ensaio de José Iges intitulado Fluxus y la música: un vasto territorio a explorar (2002), como a utilização de resíduos da atividade concertista tradicional com o uso de objetos cotidianos, a infusão do conceitualismo na dimensão da música e as vinculações dos elementos musicais de Fluxus com o teatral, o poético e o vídeo, ou seja, com elementos da intermídia proposta por Dick Higgins ${ }^{4}$. As práticas artísticas sonoras ${ }^{5}$ pressupõem assim uma ligação a essa noção de intermídia, “[...] pois ao contrário de uma 'arte multimídia', ela não supõe uma simples adição ou superposição de meios e/ou tecnologias, mas como escreve José Iges, consiste numa prática artística que se vale de estratégias de intersecções" (STOLF, 2011, p. 292).

Deste modo, pensarmos em usos heterogêneos do som para abordar algumas de nossas produções artísticas envolve lidar com

múltiplas possibilidades de usos do som a partir do conceito de proposição sonora e de sua inserção no campo artístico [...], o qual solicita também relações específicas com outras áreas e contextos [...]. [...] Pois pensar um trabalho como proposição também implica em concebê-lo como algo que não se dissocia de seu processo, como algo efêmero, situacional e que pode circular em alguns contextos de um modo quase imperceptível e sutil (STOLF, 2011, p. 293-294).

Por fim, a construção de publicações sonoras envolve relações entre texto e som (presente materialmente ou não), implicando relações entre o disco enquanto trabalho artístico (CELANT, 1977) e o livro/publicação de artista como obra e/ou sequência de 
espaço-tempo (CARRIÓN, 2011). Germano Celant (1977), no catálogo da exposição The Record as Artwork: from Futurism to Conceptual Art, a partir das propostas conceituais dos anos 1960, assinala que o disco contribuiu para a concentração de um componente do trabalho artístico - o som -, e enriqueceu a matriz das ferramentas linguísticas disponíveis para expandir os elementos visuais, possibilitando ampliar preceitos artísticos. Para o autor, o disco propiciou uma amplificação acústica do trabalho artístico, contribuindo para uma difusão da arte (da mesma maneira que o livro, o telegrama, o vídeo, a fotografia e o filme). Nesse sentido, Anne Moeglin-Delcroix (2006) sublinha que o livro de artista é capaz de conservar os vestígios de outras atividades artísticas intermidiáticas, pressupondo assim constituições e características heterogêneas, o que dialoga diretamente com as práticas artísticas sonoras, que também se valem de estratégias intermídia e da intersecção como processo constitutivo. ${ }^{6}$

\section{Espaço sonoro atravessado ${ }^{7}$}

Se o uso heterogêneo do som nas práticas artísticas já possui uma característica de intersecção, isso se torna ainda mais evidente quando são acionados dispositivos que criam espaços sonoros perpassados por múltiplas vozes e sonoridades. $\mathrm{O}$ espaço radiofônico, por exemplo, é proposto como experimental e participativo em muitos textos e experiências artísticas que o compreendem de maneira ampliada. Neste sentido, apontam para outras potencialidades em seu uso, considerando a transmissão como potência de criação desses espaços sonoros atravessados e fronteiriços.

Como coloca Breitsameter, as primeiras experimentações com o espaço radiofônico nos Estados Unidos antes da Primeira Guerra Mundial eram muito distintas do que compreendemos por rádio na atualidade. Segundo a autora, “[...] chamadas e respostas aconteciam na mesma frequência, às dezenas e simultaneamente, lembrando uma sala de bate-papo virtual em que todos se ouviam ao mesmo tempo [...]" (BREITSAMETER, 2007, p. 61, trad. nossa). A partir disso, a autora faz referência ao conflito entre duas arquiteturas possíveis para o meio, discussão que nos anos 1920 ainda estava muito presente: o conceito de rádio enquanto transmissão contra a noção de rádio enquanto espaço com múltiplos usuários ${ }^{8}$. No primeiro modelo, um transmite enquanto 
muitos escutam, dentro um sistema de via única, enquanto que no segundo, muitos se comunicam com muitos, em um meio de duas ou múltiplas vias. Bertolt Brecht, em seu ensaio O rádio como um aparato de comunicação, de 1932, faz referência a essa mesma questão quando pensa sobre como o rádio poderia ser.

[...] rádio é um meio de uma via, quando deveria ser de duas. É puramente um aparato para distribuição, para a mera difusão. Então eis uma sugestão positiva: mude este aparato de distribuição para comunicação. Isto quer dizer, seria como se ele soubesse como receber e também como transmitir, como deixar o ouvinte falar e também ouvir, como trazê-lo para uma relação ao invés de isolá-lo (BRECHT, 1932, trad. nossa).

Frente a essas duas arquiteturas possíveis, Breitsameter afirma que a escolha pelo desenvolvimento do rádio enquanto transmissão é resultado de decisões políticas feitas na Alemanha e em outros países nos anos 1920, motivadas principalmente pelo temor existente na época do efeito propagandístico do meio e da incitação da população em geral contra os regimes estabelecidos (BREITSAMETER, 2007, p. 61, trad. nossa). Assim, o princípio da transmissão como monopólio do estado ou como via única executada por poucos permitia um maior controle das ondas sonoras e do que estavam promovendo. Nos anos 1930, Bertolt Brecht e Rudolf Arnheim foram importantes críticos deste uso do rádio, levando o segundo a definí-lo da seguinte maneira: "rádio, um fala sem ouvir e todos os outros escutam sem poder falar.” (ARNHEIM, 1979 apud BREITSAMETER, 2007, p. 61, trad. nossa).

Diante disso, muitas práticas sonoras e artísticas propõem desvios desse molde de via única, criando outras maneiras de se relacionar com o espaço radiofônico. O que interessa nestas experimentações é trazer à tona o potencial de participação, interação e de construção processual e coletiva. Entretanto, Breitsameter comenta sobre a dificuldade da utilização de uma construção aberta e colaborativa em um contexto de mídia tradicional, já que o resultado é espontâneo, múltiplo e inesperado, sem controle prévio das contribuições que são recebidas, e “[...] as objeções a esses projetos de rádio continuam enraizadas no mesmo medo do efeito propagandístico do radio, como era o caso nos anos 1920 [...]" (BREITSAMETER, 2007, p. 68, trad. nossa). 
A interessante experiência pioneira de rádio online, Horizontal Radio, de 1995, é um exemplo do emprego de um sistema de transmissão de múltiplas vias. A ação utilizou a Internet juntamente com outros meios de comunicação, englobando linhas telefônicas, radiofonia, transmissão via satélite e redes ISDN ${ }^{9}$. O emprego de múltiplas tecnologias e a criação de uma rede entre elas teve como finalidade construir um espaço heterogêneo, processual e participativo. A ação de vinte e quatro horas de duração foi coordenada pela ORF (Radio Nacional da Áustria), com a participação de trinta estações de rádio, oito servidores de Internet e de quase uma centena de artistas colaborando a partir dos seus estúdios, em várias partes do mundo. O Canadá foi um dos países participantes, com pontos em Edmonton, Vancouver e Québec. No Québec, a organização partiu do Avatar, centro de artistas voltado para a arte sonora e eletroacústica ${ }^{10}$. Cada um dos pontos da rede recebia e transmitia simultaneamente, podendo fazer alterações e inserções no sinal e redistribuí-lo para que pudesse ser ouvido e modificado em outros locais.

Essa expansão do conceito de rádio e a percepção de que outras tecnologias de comunicação e transmissão podem ser empregadas em práticas artísticas está no cerne das artes da transmissão, o que abrangeria "trabalhos nos quais o ato de transmitir e receber não é somente significativo, mas está no cerne das intenções do/da artista" (JOSEPH-HUNTER, 2015, p. 11). Gale Joseph-Hunter faz parte do centro de artes Wave Farm, localizado em Acra, Nova Iorque, o qual empreende um diálogo intenso com as práticas sonoras desenvolvidas no Canadá e no Québec. Wave Farm foi o centro responsável por desenvolver e propor o termo artes da transmissão, a partir das produções de seus participantes que são inteiramente voltadas para as ondas sonoras. $\mathrm{O}$ termo engloba também a rádio arte, mas vai além das frequências AM e FM, pois seus praticantes se interessam "[...] por um conceito expansivo do rádio e com frequência buscam sua desmistificação e inovação através de uma relação 'faça você mesmo' e prática com a tecnologia de transmissão [...]" (JOSEPH-HUNTER, 2015, p. 11). As tecnologias empregadas podem ser tanto rádios $\mathrm{AM}$ e FM, quanto rádios especializados (como radiotransmissores), televisão, tecnologias de telefonia e de celular, satélite, entre outras possibilidades. 


\section{Como falar entre fronteiras ${ }^{11}$}

O convite à participação através de dispositivos de transmissão esteve presente na ação Como falar entre fronteiras, de 2015, que resultou na publicação impressa e sonora de mesmo título, de 2016. Essa proposição partiu de uma relação estreita e de uma vivência de muitos anos na tríplice fronteira entre Brasil, Paraguai e Argentina. Assim, o trabalho partiu de um lugar específico e de uma relação estabelecida "com seu entorno para então formar seu significado e complexidade, encontrando nessa relação sua potencialidade" (BARRETO; GARBELOTTI, 2004, p. 113).

A escuta das sonoridades que atravessam esse território foi crucial para perceber como nele se configuram espaços sonoros atravessados e extremamente complexos. A escuta da programação das rádios das cidades da tríplice fronteira permitiu um importante encontro com o espaço transfronteiriço, coabitado por transmissões de vários países e por distintas línguas, perpassadas por diferentes pontos de vista. Estes partiam de distintos lugares de fala (RIBEIRO, 2017), que configuravam imediatamente diferentes lugares de escuta, em um movimento de uma escuta fronteiriça. Entretanto, apesar de ocuparem um mesmo espaço sonoro, essas transmissões continuavam voltadas para os seus países específicos, com pouco ou nenhum diálogo empreendido entre elas.

Porém, há uma sonoridade fronteiriça e variante presente no próprio falar que acontece cotidianamente nessa região, onde se aproximam os idiomas oficiais dos três países: português, no Brasil; espanhol, na Argentina; e espanhol e guarani, no Paraguai. Essa zona de fronteira é atravessada por outras vozes, essas "menos nítidas e oficiais" (COUTINHO, 2003, p. 69), cada uma com suas particularidades e contextos específicos, incluindo o portunhol, resultante da influência entre português e espanhol, o jopara ${ }^{12}$, em que espanhol e guarani ou português e guarani se misturam de forma muito fluida e subjetiva, e ainda os diversos usos dos guaranis ${ }^{13}$ entre outros atravessamentos. Assim, a proposta passou pela percepção do potencial das ondas sonoras e do falar por entre idiomas de atravessar fronteiras. Como criar um dispositivo artístico que levasse esse potencial ao seu limite, estremecendo a separação entre países, aproximando distintos pontos de vista e experiências? Que apontasse para o caráter construído e arbitrário das barreiras estabelecidas? 
Como falar entre fronteiras, de 2015 (fig. 1), foi uma ação e intervenção sonora pensada e proposta para a região da tríplice fronteira entre Brasil, Paraguai e Argentina, mais especificamente para o ponto de confluência entre os rios Paraná e Iguaçu. Em cada uma das margens dos municípios fronteiriços (Foz do Iguaçu/PR, no Brasil, Puerto Iguazu, na Argentina e Presidente Franco, no Paraguai) estão localizados os Marco das Três Fronteiras, estruturas de concreto com as cores nacionais que indicam o território de cada país. Este é um ponto turístico importante da região, a partir do qual visitantes e moradores podem observar o encontro dos rios e a fronteira tríplice. Entretanto, apesar da proximidade de poucos metros entre as nações, não é permitido atravessar a linha fronteiriça imaginária. De fato, para chegar de uma margem à outra de maneira legal, é preciso atravessar por via terrestre, cruzando necessariamente uma série de pontos de controles, com suas checagens, regulações e documentações.

Porém, as ondas sonoras não respeitam estas barreiras estabelecidas, escapam pelo ar e rasgam impedimentos, criando outros territórios, diálogos e possibilidades. A intervenção consistiu, assim, na instalação temporária e simultânea de três pedestais com radiotransmissores, cada um em uma das margens dos três países.
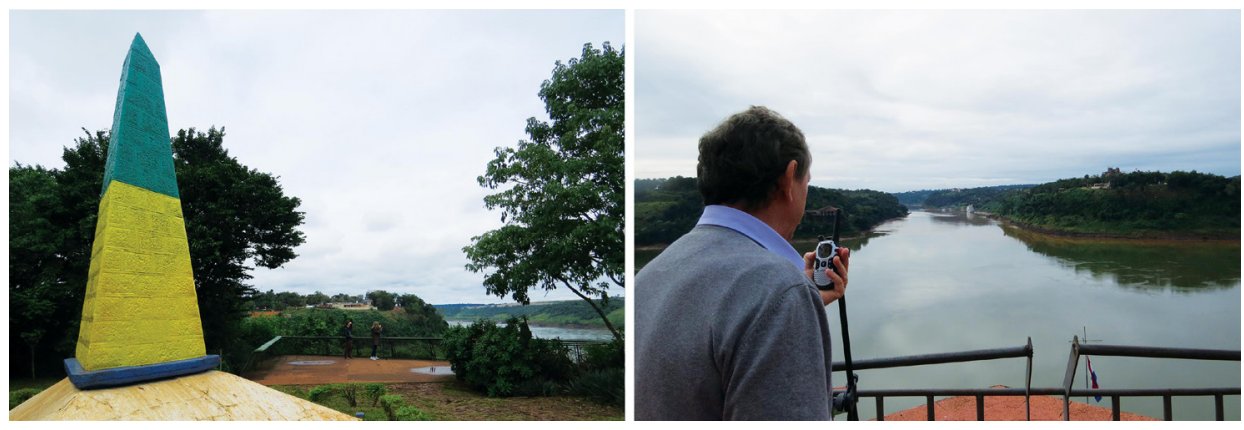

Fig. 1. Imagens de registro da ação Como falar entre fronteiras no Marco das Três Fronteiras do Brasil e do Paraguai, respectivamente. Fran Favero, 2015. Fotos: Fran Favero.

Através das ondas de frequências abertas e livres, cada aparelho recebia e transmitia sons, permitindo a troca sonora entre os três pontos e, portanto, entre os países. O dispositivo de múltiplas vias possibilitava o acontecimento de conversas transfronteiriças e 
multilíngues em um sinal aberto, sendo, portanto ouvidas e transmitidas simultaneamente em todos os pontos. Moradores/as, turistas, vendedores/as e passantes eram convidados/ as a falar entre fronteiras, através da distribuição de panfletos em português, espanhol e guarani que chamavam à participação. Muitas conversas aconteceram, enquanto que outras participações envolveram a fala sem resposta, ou ainda apenas a escuta, com grupos de pessoas que se aglomeravam em torno do radiotransmissor aguardando as transmissões dos outros lados.

Desta ação resultou a publicação impressa e sonora Como falar entre fronteiras - Como hablar entre fronteras - Rembe'y apytépe, de $2016^{14}$ (Fig. 2), proposta em forma de souvenir postal em diálogo com os cartões-postais do ponto turístico onde ocorreu a ação. Além das fotografias das pontes, alfândegas e da ação em si, a publicação conta ainda com um mini-CD em que podem ser ouvidos trechos das conversas e transmissões.

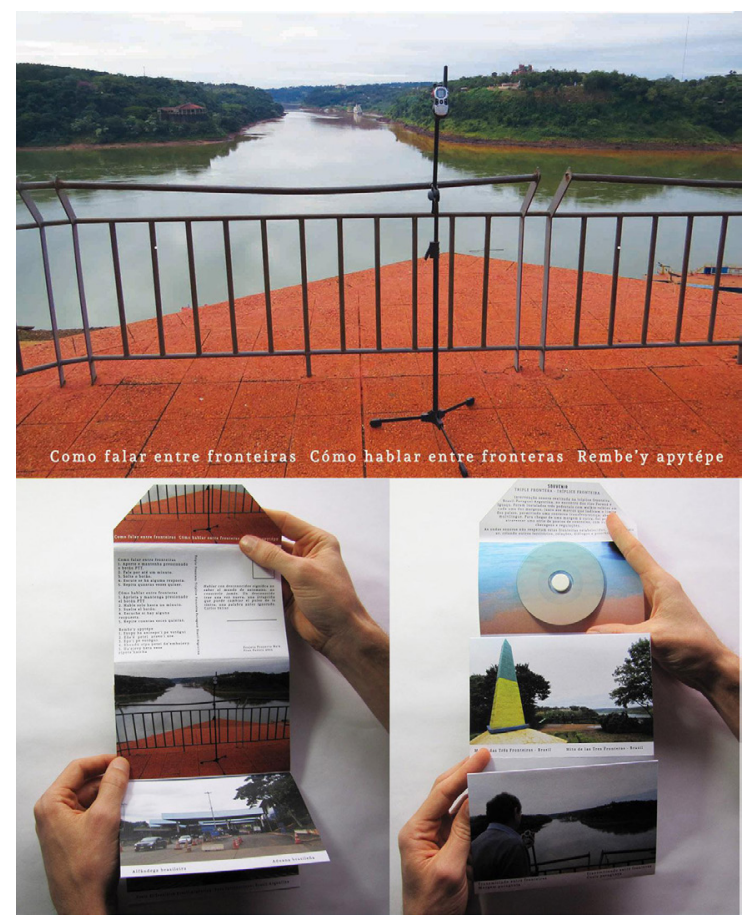

Fig. 2. Como falar entre fronteiras - Cómo hablar entre fronteras - Rembe'y apytépe. Fran Favero, 2016. Capa da publicação na imagem superior e, abaixo, frente e verso do souvenir postal aberto. Fotos: Fran Favero. 
Esta foi uma ação experimental, um convite à participação, à escuta, à troca, em um movimento de conversa com desconhecidos, o que "[...] traz uma voz nova, uma irrupção que pode mudar o pulso da terra, um gesto que nos faz torcer o já sabido, uma palavra antes ignorada [...]" (SKLIAR, 2014, p. 10). A ação e a publicação permitem que múltiplas vozes, línguas e particularidades ganhem corpo e alcançem outros territórios, criando desvios e curvas, dobras e redobras nas fronteiras estabelecidas, possibilitando a constituição de territórios abertos, relacionais, sempre em processo e em derivação.

\section{Escuta infra-mince, escutas do infra-ordináriox ${ }^{15}$}

As publicações sonoras - The Sonic Body: Figures 1-12 (2011), de Brandon LaBelle e Crackers (2001) (fig. 3), de Christof Migone -, possuem processos de construção que envolveram desdobramentos e ressonâncias de ações e situações entre processos de escuta e participações coletivas, sendo atravessadas pela proposição de escuta para o que escapa, roça, respira ou estala, transitando entre uma escuta infra-mince e escutas do infra-ordinário.

Georges Perec (2008) pergunta-se como descrever o que se passa a cada dia e o que se repete, como interrogar o que é comum, cotidiano e infra-ordinário, como falar desse ruído de fundo, incessante? "Mas onde está nossa vida? Onde está nosso corpo? Onde está nosso espaço?” (PEREC, 1989, p.11, trad. nossa). Talvez, como propõe Perec, podemos tentar pensar relações com estas interrogações começando por fazer um inventário de nossos bolsos ou bolsas, perguntando sobre as procedências, os usos e os futuros de cada objeto encontrado, perguntando onde, quando, por que e como vivemos, respiramos, caminhamos, descemos as escadas, sentamos à mesa para comer ou deitamos em camas para dormir.

Interrogar um ruído de fundo implica uma posição de escuta rasteira, que vasculha, sonda e desliza. Uma escuta inquieta, que fisga e recolhe fricções, assombros por microacontecimentos sonoros e até mesmo quase insonoros. Mas, como interrogar o som de "Calças de veludo - / seu zunido agudo (no andar) pelo / roçar das duas pernas"16? Como ouvir um som infra-mince e escutar uma "separação infra-mince indicada pelo som", proposta por Duchamp? 
Em The Sonic Body: Figures 1-12, Brandon LaBelle ${ }^{17}$ apresenta como publicação uma "coleção de traços audíveis de corpos dançantes" (LABELLE, 2011, capa da publicação, trad. nossa) reunida em um CD de áudio com uma capa-pasta e um livreto, contendo um texto acerca de seu processo de construção e desdobramento em publicação, notas de campo para um esboço do trabalho, indicando-se também as faixas que compõem o CD e os/os participantes que as produziram, entre outros créditos ${ }^{18}$. A publicação sonora compila os ruídos de movimentos de pessoas ouvindo músicas (em fones de ouvido) e dançando (com alguns instantes de vocalizações), gravados de modo a formar espécies de "identidades acústicas, destacando a dança como uma forma de tradução" (LABELLE, 2011, capa da publicação, trad. nossa).

The Sonic Body é um trabalho que visa a fisicalidade do som, como um processo de ingestão, entrada, uma fome de escuta e, finalmente, a reação incorporada, uma vitalidade sensual que refigura a presença do corpo em um micro-evento energético. [...]

Uma série de experimentos de gravação foram feitos ao longo de 2009 e 2010, convidando vários participantes, cada um dos quais recebeu a tarefa de dançar enquanto ouvia faixas musicais de sua escolha através de fones de ouvido. A ideia era capturar, através da gravação de áudio, os movimentos físicos de cada participante, dentro de diferentes configurações, e finalmente eliminar o material musical completamente do trabalho, de modo a concentrar-se no corpo em movimento como um acontecimento sonoro. (LABELLE, 2011, capa da publicação e p.4, trad. nossa)

Cada faixa de Sonic Body consiste em uma destas experiências, indicando-se a música ${ }^{19}$, o/a participante que escuta/dança e o ambiente da ação, sendo intitulada como Figure 1 e assim sucessivamente. As últimas duas "figuras" (Figure $11 \& 12$ ) são indicadas/intituladas como "amplifications / imaginary" ("amplificações / imaginário"), em que são registradas duas ações em grupo. Uma das ações foi gravada em um grande espaço de um teatro, com quatro participantes, que ao invés de escutarem música, escutam através de fones de ouvido wireless (com microfones dispostos no espaço, em total escuridão) seus próprios ruídos/ações e a fisicalidade do espaço, explorando esses movimentos como "acontecimentos sonoros". Já numa segunda ação, gravada em um espaço de dança, também com quatro participantes, mas num espaço iluminado, não há mais fones de ouvido, sendo que aos participantes foi solicitado para "imaginar seus 
movimentos como ações de geração de som" (LABELLE, 2011, p.5, trad. nossa), em que os movimentos de cada parte do corpo são pensados não como ações visuais, mas como como "um movimento de ruído imaginado" (LABELLE, 2011, p.6, trad. nossa). Sobre esse processo em Sonic Body, LaBelle assinala que escutar “[...] pode não ser apenas um ato dirigido para fora, para o mundo, mas igualmente um processo interno, de sintonizarse e cercar-se; escutar pode procurar por uma parceria audível encontrada no mundo [...]" (2011, p.6, trad. nossa).

Dialogando com o projeto e reflexões de LaBelle, Christof Migone, no processo de construção do projeto e da publicação Crackers (2001), coloca um anúncio em um jornal semanal, no rádio e também através de uma rede da Galeria 101, em Ottawa (Canadá), perguntando: "Você estala seus dedos? seu pescoço? suas costas? seus joelhos? seus cotovelos? seus tornozelos? seu quadril? e seu...?" (2005, p.80, trad. nossa). A partir dos anúncios, Migone reúne um grupo de nove participantes para sessões de gravação, que consistiram em entrevistas e em uma "sessão de ruídos" - ou como propõe Migone, uma "sessão de estalos" (“cracking session").

O projeto Crackers foi gravado em 1997, durante uma residência do artista na Galeria 101, em Ottawa, editado (1998) no Avatar (um centro de arte eletrônica e áudio-arte, em Québec) sendo apresentado inicialmente como instalação na exposição coletiva Incredibly Soft Sounds na mesma galeria (curadoria de Emmanuel Madan), em 1998. A versão enquanto instalação também apresentava um vídeo do artista estalando repetidamente seu tornozelo direito durante vinte minutos, exposto como uma projeção no nível do tornozelo. Desdobra-se também em uma performance, em que Migone apresenta duas projeções videográficas, uma da ação pré-gravada e outra da ação executada ao vivo, nas quais estala seu tornozelo direito, junto com as gravações em áudio dos estalos de 1997. ${ }^{20}$ Crackers desdobra-se ainda em um CD de áudio (finalizado e mixado em 2000, sendo lançado pela Locust Music, em 2001), acompanhado por um folheto com créditos e desenhos da artista Onya Hogan-Finlay. 

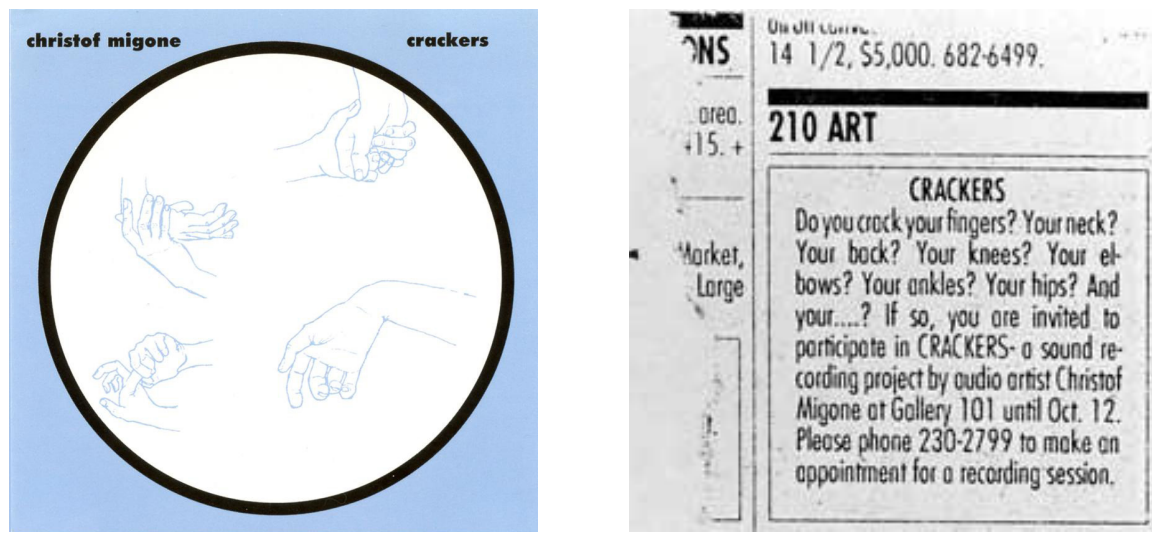

Fig. 3. Crackers (capa de CD e anúncio em jornal). Christof Migone, 2001.

Fonte: http://christofmigone.com/crackers_ottawa/.

Para Migone, seu projeto produz uma espécie de

retrato de uma cidade através dos ossos de seus cidadãos. Esta é uma forma específica de paisagem sonora [soundscape], é uma crackerscape. Os retratos apresentam formas de comportamento que navegam nervosamente entre o controlável e o incontrolável. [...] Com CRACKERS: uma articulação é o local onde os ossos articulam uma tensão. Crackers são compulsivos sobre a liberação dessa tensão. Conforme o som dos estalos ecoam, alguns estremecem, outros sentem alívio. Em todos os casos, um estalo é quando e onde algo quebra. [...] Um cracker é uma edição de osso/Um cracker é uma pausa quebrada. (MIGONE, http:// christofmigone.com/Crackers_Ottawa/, trad. nossa)

Mas, como perceber e escutar essas "pausas quebradas”, esses estalos sem matriz lingüística e sem aterrissagem precisa (quase secretos), esses ruídos intersticiais (dentro/ fora do corpo)? Steve Roden nos dá uma pista, ao afirmar que as propostas sonoras têm “[...] o potencial de ampliar a percepção de uma pessoa de um espaço (ou talvez até do mundo), através da experiência da escuta - e escutar focado aumenta a experiência [...]" (2005, trad. nossa). E escutar desfocado? O que seria um desfoque na escuta? Talvez implique estar imerso/a numa "crackerspace", entre tensão (foco) e pausa (desfoque), onde a própria escuta pode "estalar" e imaginar. 


\section{Panquecas fantasmáticas ${ }^{21}$}

Marcel Duchamp escreve que "Podemos ver/olhar o ver", "Não podemos ouvir o ouvir" (2007, p. 37, trad. nossa). Dialogando com Duchamp, o artista Christoph Korn sublinha que "Não vemos o som, somente o escutamos. No melhor dos casos, podemos ver sua fonte, mas não o próprio som.” (2008, trad. nossa). E aponta que se o som é invisível, o mundo sonoro instiga e "dispara" nossa imaginação. Korn afirma que escutar significa "antecipar", em que o som tem sempre algo de impreciso e durante o processo de percebê-lo somente se concretizam algumas partes de sua materialidade. Há sempre um trecho "impronunciável” do som: “[...] temos uma sensação intuitiva de suas características, muito mais do que podemos explicar nos mínimos detalhes. Uma premonição nos sussurra." (2008, trad. nossa). Em Sinister Resonances, David Toop investiga as características espectrais do som e suas relações com a memória e seus rastros, partindo da premissa de que "[...] o som é uma assombração, é um fantasma, é uma presença cuja localização no espaço é ambígua e cuja existência no tempo é transitória. [...] Escutar é, depois de tudo, sempre uma forma de escuta escondida." (2010, p.XV, trad. nossa)

O processo de Panquecas fantasmáticas pressupõe esse traço/rastro premonitório e furtivo da escuta, seu trecho "impronunciável" e sua inquietante intangibilidade. Ao mesmo tempo, envolve relações com uma escuta do infra-ordinário, na medida em que o processo da proposição sonora foi desencadeado na ocorrência de uma experiência de escuta durante uma situação culinária cotidiana, quando estava fazendo panquecas para o almoço, em maio de 2002. Quando espremia as panquecas com a espátula, pressionandoas contra a frigideira, elas faziam assobios e ruídos quase fantasmagóricos e essas sonoridades me fisgaram. ${ }^{22}$ Esta experiência, somada a outros processos e projetos, desencadeou uma série de percepções, pensamentos, sentidos e imagens, que por sua vez, suscitaram o interesse em investigar o som em meu processo artístico, como catalisaram anotações e reflexões sobre a construção de outras proposições sonoras, instigando o desenvolvimento do projeto e da publicação FORA [DO AR] (2002-2004) (fig. 4). ${ }^{23}$

Panquecas fantasmáticas passou a intitular uma das faixas da publicação sonora FORA [DO AR], que é composta por um CD de áudio e material impresso, com trinta 
e três faixas que podem ser desdobradas em ações, micro-intervenções urbanas (através de carros de som ou bicicletas que fazem anúncios sonoros), em micro-intervenções domésticas, em instalações, vídeos e textos. Tem tiragem de quinhentos exemplares e agrupa proposições sonoras que investigam a palavra em situações cotidianas (os ruídos de fundo da fala, a escrita e as fissuras da ficção), propondo também pensar uma "escuta porosa", que tenta absorver ruídos/silêncios do entorno e variações sonoras entre barulho, ruído e rumor.

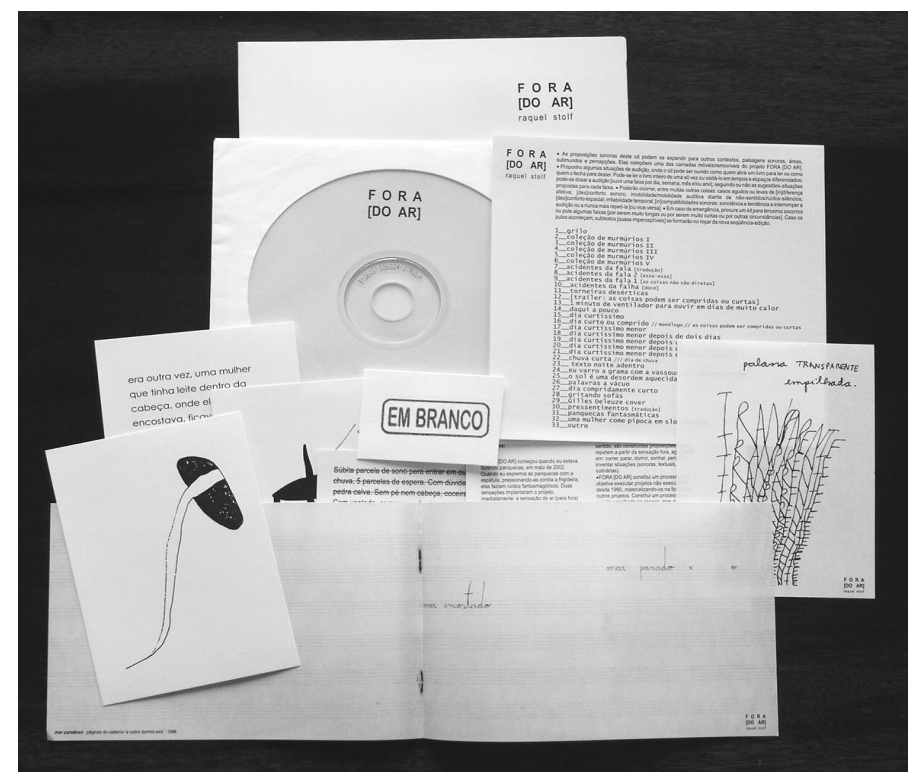

Fig. 4. FORA [DO AR]. Raquel Stolf, 2002-2004. Foto: Raquel Stolf.

A proposição foi veiculada também enquanto instalação sonora homônima (20022004), sendo emitida de duas pequenas caixas de som brancas, suspensas e próximas do chão. ${ }^{24}$ Já em 2009, propus um desdobramento de Panquecas fantasmáticas como ação sonora realizada no Contemporão Espaço de Performance, em Florianópolis, no evento coletivo Bem Bom (curadoria de Adriana Barreto e Yiftah Peled). Preparei panquecas na cozinha dos coordenadores do espaço (Elaine de Azevedo e Yiftah Peled), sem ser vista pelo público (que desconhecia a fonte de emissão sonora), produzindo ruídos que 
foram amplificados e transmitidos em tempo real para três caixas de som posicionadas no espaço expositivo, durante 20 minutos. No final da ação, as panquecas foram servidas ao público. ${ }^{25}$

Em 2011, a receita-partitura com o processo de sonorização de panquecas foi publicada na Revista Recibo 23 - Receitas e Roteiros (ed. Traplev e Carla Zaccagnini). Esta versão do trabalho já lançava a proposta de um mini-curso-demonstração, e ao mesmo tempo, apresentava-se enquanto receita-partitura e proposição para um possível desdobramento doméstico a ser executado e experimentado pelos leitores-ouvintes da Revista Recibo. ${ }^{26}$

Por fim, entre outros desdobramentos, em 2016 realizei a oficina-proposição sonora Panquecas fantasmáticas (fig. 5), a convite do projeto PORTUÁRIO - Encontros de Pesquisa e Produção em Artes Visuais, coordenado por Sarah Uriarte e Kim Coimbra, na Galeria Municipal de Arte de Itajaí. A oficina teve início com uma conversa acerca de projetos que envolvem publicações sonoras e seus desdobramentos ou planos de partida em ações, intervenções, instalações, proposições e outras possibilidades (com uma sessão de audição de extratos de publicações). Foram também propostos um exercício de escrita ${ }^{27}$ uma caminhada pelo espaço da casa (Galeria Municipal de Arte de Itajaí) e a prática coletiva da receita-partitura de Panquecas fantasmáticas (utilizando-se liquidificador, fogareiro, frigideira, ingredientes para panqueca e utensílios da receita). Durante a proposta de prática de sonorização de panquecas, demonstrou-se os detalhes do preparo e em seguida o grupo participou da experiência. Ao final da oficina, as panquecas foram consumidas pelos participantes. ${ }^{28}$ 

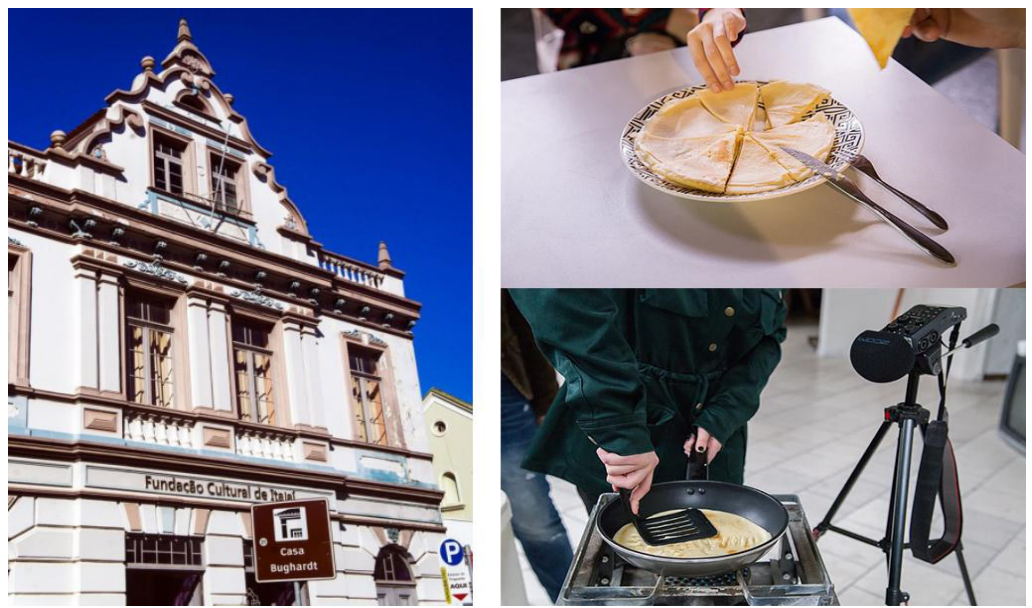

Fig. 5. Registros da oficina-proposição sonora Panquecas fantasmáticas no projeto PORTUÁRIO, na Galeria Municipal de Arte de Itajaí. Raquel Stolf, 2016. Fotos: Sarah Uriarte.

Ressonâncias e outras "fomes de escuta" (LABELLE, 2011): em todos os desdobramentos da proposição Panquecas fantasmáticas, algo que fisgou suas ocorrências e experiências de escuta foi uma espécie de assobio sem boca, um ruído infraagudo e relações ambíguas entre fim e infinitude, que ressoaram entre os comentários e conversas com os/as ouvintes e/ou participantes da oficina-proposição. Em alguns dos desdobramentos, a situação "esquizofônica" ${ }^{29}$ de por vezes não se saber de onde vinha (ou o que produzia) o som, apontava para a escuta de sons sem corpo (ou de "corpos sonoros" inquietantes), de microruídos sem paradeiro. Ruídos que parecem vir da barriga, do corpo e da pele de uma panqueca inchada/inflada, que estala e se esvazia. Sonorizar e escutar panquecas envolve um humor e non-sense (escutar um som como fantasma infraordinário, que sonda o não-sentido), como também implica que "[...] escutar nos permite acesso constante a um mundo menos estável, omnidirecional, sempre em estado de se tornar e recuar, conhecido e desconhecido.” (TOOP, 2010, p.37-38, trad. nossa).

\section{Intersecções}

Os processos de construção e apresentação de publicações sonoras envolvem assim uma série de desdobramentos - como em FORA [DO AR] e na proposição Panquecas 
fantasmáticas, de Raquel Stolf -, podendo também ser catalisadas e editadas pelos desdobramentos de projetos - como em Sonic Body, de Brandon LaBelle e em Crackers, de Christof Migone -, propondo situações de escutas do infra-ordinário e infra-mince, com seus microruídos furtivos; ou ainda em Como falar entre fronteiras, de Franciele Favero, em que foram propostas situações de escuta e fala fronteiriça, com a constituição de espaços sonoros atravessados e múltiplos, que se desdobram e seguem reverberando na publicação sonora.

Sobretudo, nas publicações sonoras aqui investigadas, são agenciados diferentes processos de escuta, entre o infra-ordinário e o infra-mince, entre o lugar de escuta em espaços fronteiriços, que pressupõem trânsitos entre contextos e falas atravessadas, pensando-se e praticando-se a escuta como situação, campo e espaço de participação.

\section{Referências}

ARIZA, Javier. Las imágenes del sonido: una lectura plurisensorial en el arte del siglo XX. Cuenca: Ediciones de la Universidad de Castilla-La Mancha, 2008.

ASSIS, Cecy Fernandes de. Ñe'ẽryru: avañe'ẽ-portuge/portuge-avañe'ẽ. Dicionário: guarani-português/ português-guarani. São Paulo: Cecy Fernandes de Assis. Edição própria, 2008.

BARRETO, Jorge Menna; GARBELOTTI, Raquel. Especificidade e (in)tradutibilidade. In: XIII Encontro Nacional da ANPAP. Arte em pesquisa: especificidades. Brasília: Editora da Pós-graduação em Arte da Universidade de Brasília, 2004. v. 1. p. 111-115.

BREITSAMETER, Sabine. From transmission to procession: radio in the age of digital networks. In: LABELLE, Brandon; JENSEN, Erik Granly (orgs.). Radio territories. Los Angeles: Errant Bodies Press, 2007. p. 56-70.

BRECHT, Bertolt. Der rundfunk als kommunikationsapparat [The radio as an apparatus of communication]. In: Bjitter des Hessischen Landestheaters Darmstadt, n. 16, 1932. Disponível em: $<$ http://www.lee-web.net/pdfs/AoT_supplement_2013.pdf $>$. Acesso em: 10 de mar. 2019.

CARRIÓN, Ulises. A nova arte de fazer livros. Belo Horizonte: Ed. Andante, 2011.

CELANT, Germano. The Record as Artwork: from Futurism to Conceptual Art (cat. de exposição). Texas: Fort Worth, The Fort Worth Art Museum, 1977.

COSTA, José Manuel. Arte Sonoro. In: Exit Express: Revista de Información y Debate sobre Arte Actual. \# 54, Octubre 2010. 
COUTINHO, Marcelo. Deambulações sobre o contorno: ensaio para ser lido em voz alta, simultaneamente, por três pessoas. In: Revista Item - Fronteiras, Rio de Janeiro: Espaço Agora/Capacete, v. 6, p. 66-72, 2003.

DUCHAMP, Marcel. Notas. Madri: Tecnos, 1989.

. Duchamp du signe: Ecrits Réunis et présentés por Michel Sanouillet. Paris: Flammarion, 2007.

FAVERO, Franciele. (D)espacio. Trabalho de Conclusão de Curso (Graduação) - Universidade do Estado de Santa Catarina, Centro de Artes, Curso de Artes Visuais, Florianópolis, 2015. Disponível em: <http://pergamumweb.udesc.br/dados-bu/000006/0000060c. pdf>. Acesso em: 20 mar. 2019.

IGES, José. Arte sonoro: un arte de intersecciones, 2007. Disponível em: $<$ http://joseiges. com/?page_id=36>. Acesso em 30 de Jan. 2019.

JOSEPH-HUNTER, Galen. Air design, air rights and air support: foundations of transmission art. In: Galen Joseph-Hunter, Penny Duff e Maria Papadomanolaki (orgs.). Transmission arts: artists and airwaves. New York: PAJ Publications e free103point9, 2011.

KIM-COHEN, Seth. In the Blink of an Ear: Toward a Non-Cochlear Sonic Art. New York: Continuum, 2009.

KORN, Christoph. Reflections on Sound. 2008. Disponível em: <http:/www.gruenrekorder.de/fieldnotes/?p=archive\&lang=en $>$. Acesso em: 13 set. 2009.

KOSTELANETZ, Richard [et al.] The dictionary of the avant-gardes. Chicago: a cappella books, 1993.

LABELLE, Brandon. Background noise: perspectives on sound art. New York, London: Continuum Books, 2006.

. The Sonic Body: Figures 1-12. Berlim: Errant Bodies Records, 2011. 1 CD.

. <http://www.brandonlabelle.net/the_sonic_body.html>.Acesso em: 15 mai. 2018.

MIGONE, Christof. Crackers. Chicago: Locust Music, 2001. 1 CD.

. <http://christofmigone.com/Crackers_Ottawa/>. Acesso em: 20 mar. 2018.

MOEGLIN-DELCROIX, Anne. Qu'est ce qu'un livre d'artiste? In: MOEGLIN-DELCROIX, Anne. SUR LE LIVRE D'ARTISTE. Articles et Écrits de Circonstance - 19812005. Marseille: Le Mot et Le Rest, 2006.

PEREC, Georges. L'infra-ordinaire. Paris: Éditions du Seuil, 1989.

RIBEIRO, Djamila. O que é lugar de fala?. Belo Horizonte: Letramento: Justificando, 2017.

RODEN, Steve. Active Listening. 2005. Disponível em: <http://www.inbetweennoise. com/activelistening.html>. Acesso em: 20 mar. 2018.

SKLIAR, Carlos. Hablar con desconocidos. Barcelona: Ed: Candaya Abierta 6, 2014. 
SCHAFER, R. Murray. A afinação do mundo: uma exploração pioneira pela história passada e pelo atual estado do mais negligenciado aspecto de nosso ambiente: a paisagem sonora. São Paulo: Editora Unesp, 2001.

STOLF, Maria Raquel da Silva. Entre a palavra pênsil e a escuta porosa [investigações sob proposições sonoras]. Tese (Doutorado em Artes Visuais). Instituto de Artes, Universidade Federal do Rio Grande do Sul, Porto Alegre, 2011. (com CD de áudio).

. FORA [DO AR]. Florianópolis: Ed. do Autor, 2004. 1 CD.

. Página gravada. In: Revista Interdisciplinar Internacional de Artes Visuais ART \& SENSORIUM. V. 3, 2016. p. 13-28. Disponível em: <http://periodicos.unespar.edu.br/ index.php/sensorium/article/view/1020>. Acesso em: 15 mar. 2017.

Sob(re) publicações sonoras e processos de escutas, entre desdobramentos. In: PRÁTICAS E CONFRONTAÇÕES - Anais do XXVII Encontro da Associação Nacional de Pesquisadores em Artes Plásticas. São Paulo: UNESP, Instituto de Artes, 2019. p.13011312. Disponível em: <http://anpap.org.br/anais/2018/content/PDF/27encontro STOLF_Maria_Raquel_da_Silva.pdf $>$.Acesso em: 31 mar. 2019.

TOOP, David. Sinister resonance: the mediumship of the listener. New York: Continuum, 2010.

ZANINI, Walter. A atualidade de Fluxus. In: Revista ARS. São Paulo, v.2, n.3, p. 1021, 2004.

\section{Notas}

1 Este artigo foi escrito em co-autoria por Franciele Favero e Raquel Stolf. Os fragmentos Como falar entre fronteiras e Espaços sonoros atravessados foram propostos por Franciele Favero e integram parcialmente seu trabalho de conclusão do Bacharelado em Artes Visuais da UDESC, de 2015, intitulado (D)espacio, bem como sua pesquisa de mestrado Rembe, atualmente em andamento no Programa de Pós-Graduação em Artes Visuais da UDESC, ambas sob orientação da Profa. Dra. Raquel Stolf. Já outras partes deste texto Escuta infra-mince, escutas do infra-ordinário e Panquecas fantasmáticas - foram propostas e parcialmente apresentadas por Raquel Stolf no XXVII Encontro da Associação Nacional de Pesquisadores em Artes Plásticas - ANPAP - 2018. Os blocos Antecedentes e Intersecções foram escritos em conjunto pelas duas autoras, a partir de reflexões presentes nas pesquisas mencionadas anteriormente.

2 Mestranda em Artes Visuais - Linha de Processos Artísticos Contemporâneos, do Programa de PósGraduação em Artes Visuais da Universidade do Estado de Santa Catarina (PPGAV/UDESC), Florianópolis, Brasil. faverofranciele@gmail.com.

${ }^{3}$ Professora nos cursos de Graduação e Pós-Graduação em Artes Visuais da Universidade do Estado de Santa Catarina - UDESC, Florianópolis, Brasil. Doutora em Artes Visuais (Poéticas Visuais) pela Universidade Federal do Rio Grande do Sul - UFRGS.

4 "Intermedia" ou "intermídia" é um termo investigado por Higgins (que remonta aos escritos de Samuel Taylor Coleridge), referenciando um texto do autor publicado em 1966 no primeiro número de um boletim da editora The Something Else Press, por ele coordenada. Richard Kostelanetz (1993) cita dois exemplos do termo intermídia: a poesia visual e a prática do text-sound. A poesia visual, por se situar entre a literatura e as artes visuais, constituindo uma "combinação" que compõe um distinct intermedium. E a prática do TextSound, que abrange a produção de textos que precisam ser "soados" e então escutados para serem "lidos", constitui um intermedium entre as artes da linguagem e as artes musicais.

${ }^{5}$ Muitas experiências com a sonoridade, principalmente aquelas realizadas nas décadas de 1970 e 1980 , passaram a ser denominadas como Arte Sonora. Entretanto, José Iges aponta o emprego desta denominação como historicista e superado, sobretudo quando são considerados os trabalhos realizados apenas por artistas 
visuais, ou mesmo por não músicos em geral. Ao invés disso, propõe "[...] que há diferentes maneiras de organizar o som no tempo e no espaço. E algumas delas são musicais e outras não" (IGES, 2007).

${ }^{6}$ Referencia-se o texto Página gravada, de Raquel Stolf, em que são abordadas relações entre disco de artista e livro/publicação de artista investigando-se relações entre texto e som, trânsitos entre palavra e silêncio, entre processos de escrita e situações de escuta e leitura, articulados em alguns trabalhos artísticos que consistem em publicações sonoras e em outras publicações de artista. Disponível em: <http://periodicos.unespar.edu.br/ index.php/sensorium/article/view/1020>. Acesso em: 15 mar. 2017.

7. As reflexões deste fragmento do texto foram propostas por Franciele Favero, a partir de trechos do seu trabalho de conclusão de curso em Artes Visuais da UDESC, intitulado (D)espacio, de 2015, e de sua pesquisa de mestrado Rembe, atualmente em andamento, no Programa de Pós-Graduação em Artes Visuais da UDESC, ambas sob orientação da Profa. Dra. Raquel Stolf.

${ }^{8}$ No texto original, em inglês, a autora emprega o termo radio as multi-user space (BREITSAMETER, 2007, p. 61).

${ }^{9}$ Informações sobre o projeto Horizontal Radio presentes em BREITSAMETER, 2007, p. 63.

${ }^{10} \mathrm{O}$ relato da experiência da participação do Québec na ação Horizontal Radio está disponível em $<\mathrm{http} / /$ www.kunstradio.at/HORRAD/hrquebec.html>. Acesso em: 20 de mar. 2019.

${ }^{11}$ Fragmento proposto por Franciele Favero a partir de trechos do seu trabalho de conclusão de curso em Artes Visuais da UDESC, intitulado (D)espacio, de 2015, e de sua pesquisa de mestrado Rembe, atualmente em andamento, no Programa de Pós-Graduação em Artes Visuais da UDESC, ambas sob orientação da Profa. Dra. Raquel Stolf.

12 Jopara designa uma variante coloquial presente principalmente no Paraguai, mas também em algumas províncias da Argentina, que mistura espanhol e guarani de maneira fluida, imbricada e muito variável.

Também pode abranger a mistura de português e guarani, falada principalmente nas regiões de fronteira entre Brasil e Paraguai. No caso do Paraguai, o jopara não está limitado a essas zonas de fronteira, estando presente em diversas regiões do país e sendo falado por grande parte da população.

${ }^{13} \mathrm{O}$ conceito Guarani abrange uma pluralidade de modalidades linguísticas e pertence à família linguística Guarani-Tupi (ASSIS, 2008, p. 47). O guarani paraguaio é língua oficial do país, juntamente com o espanhol, e é falado por mais de $80 \%$ da população, incluindo as variantes como o jopara.

${ }^{14}$ A publicação Como falar entre fronteiras - Como hablar entre fronteras - Rembe'y apytépe foi lançada em 2016 pelo Armazém, selo de publicação de artistas de Florianópolis/SC, e conta com souvenir postal, mini-CD e texto escrito por Raquel Stolf. Trecho da faixa sonora disponível em: $<$ https://soundcloud.com/fran-favero/ como-falar-entre-fronteiras-como-hablar-entre-fronteras-rembey-apytepe>. Acesso em: 20 jan. 2019.

${ }^{15}$ As reflexões deste fragmento do texto foram propostas por Raquel Stolf, a partir de seu artigo intitulado "Sob(re) publicações sonoras e processos de escutas, entre desdobramentos", In PRÁTICAS E CONFRONTAÇÕES - Anais do $27^{\circ}$ Encontro da Associação Nacional de Pesquisadores em Artes Plásticas.

São Paulo: Universidade Estadual Paulista (UNESP), Instituto de Artes, 2018. p.1301-1311.

16 "Calças de veludo - / seu zunido agudo (no andar) pelo / roçar das duas pernas é uma / separação infra-leve indicada / pelo som. (não é um som infra-leve?)" (DUCHAMP, 1989, p.22-23, trad. nossa).

${ }^{17}$ Artista, professor, escritor e editor da Errant Bodies Press. A editora é composta também pela Errant Bodies Records, que propõe publicar projetos que envolvem experimentações sonoras, "som conceitual", documentos sonoros e propostas de "intensidades espectrais, dinâmicas culturais e musicalidades errantes". ${ }^{18}$ LaBelle aponta no livreto da publicação que o projeto foi também apresentado como instalação (2010), tendo sido catalisado por um evento comissionado pela Deutschlandradio (2009), desenvolvido em colaboração com Benny Nilsen e Marcus Gammel, sendo proposto como uma "discoteca silenciosa performativa", no Maria am Ostbahnof club, em Berlim. Mais informações sobre os/as participantes diretos da publicação em: $<\mathrm{http}: / /$ www.errantbodies.org/ebr_labelle_sonic.html $>\mathrm{e}<\mathrm{http}: / /$ www.brandonlabelle.net/ the_sonic_body.html >. Acesso em: 15 mai. 2018.

${ }_{19}$ As músicas foram: Diddle Li Di, de Suzi Hyldgaard; Transmission, de Joy Division; I Get Around, de Beach Boys; Circular, de Hildur Gudnadottir; El Gran Varón, de Willie Colón; Mani, de Paco Fernandez; Young Man, de Epaksa; Ray of Light, de Madonna; Can't Get Enough of Your Love, de Barry White.

${ }^{20}$ Disponível em: $<$ http://www.christofmigone.com/html/projects_gallery/crackers.html $>$. Acesso em: 25 jul. 2007.

${ }^{21}$ As reflexões deste fragmento do texto foram propostas por Raquel Stolf, a partir de seu artigo intitulado "Sob(re) publicações sonoras e processos de escutas, entre desdobramentos", In PRÁTICAS E CONFRONTAÇÕES - Anais do $27^{\circ}$ Encontro da Associação Nacional de Pesquisadores em Artes Plásticas. São Paulo: Universidade Estadual Paulista (UNESP), Instituto de Artes, 2018. p.1301-1311. 
22 Para escuta da proposição sonora Panquecas fantasmáticas: < https://soundcloud.com/raquelstolf/ panquecas-fantasmaticas $>$. Acesso em: 15 mar. 2018.

${ }^{23}$ O projeto gráfico da publicação foi concebido por mim e executado em parceria com Aline Dias. Mais registros da publicação em: <http://www.raquelstolf.com/?p=234>. Acesso em: 26 mai. 2018.

${ }^{24}$ Apresentada na exposição individual FORA [DO AR], no Museu de Arte de Santa Catarina - MASC, em Florianópolis, 2004. Registros em: $<\mathrm{http}: / / w w w . r a q u e l s t o l f . c o m / ? \mathrm{p}=2144>$. Acesso em: 26 mai. 2018.

${ }^{25}$ A ação teve o apoio técnico de Helder Martinovsky. Registros em: $<$ http://www.raquelstolf.com/?p=685> Acesso em: 26 mai. 2018.

${ }^{26}$ Disponível em: $<$ http://issuu.com/recibo/docs/recibo23_online $>$ e $<$ http://www.raquelstolf.com/?p=687> . Acesso em: 28 mai. 2018.

27 Intitulado: "o/a fantasma do som": "1. Escrever um texto curto sob(re) o/a fantasma do som. Considerálo/la um organismo vivo, uma criatura (animal, mineral ou vegetal). Descrever seus hábitos, características físicas e mentais, modos de agir, angústias, pressentimentos, desejos, fracassos, singularidades e/ou desvios. 2. Rasurar milimetricamente algumas palavras e/ou letras do texto." (STOLF, 2015). A proposição-oficina conversou (sem que eu soubesse de antemão) com uma história peculiar do espaço da Galeria Municipal de Arte de Itajaí, que segundo os coordenadores do projeto, por ter sido uma casa anteriormente habitada por uma senhora cujo apelido era "Dona Cachorrinha", "sua" fantasma vagava pelo ambiente.

${ }^{28}$ Agradecimentos a Sarah Uriarte e a Kim Coimbra pelo apoio ao processo da oficina (e pela nova espátula). Mais registros em: <https://www.desdobraduras.com/portuario>. Acesso em: 22 mai. 2018.

${ }_{29}$ Proposto por Murray Schafer (2001), o conceito de "esquizofonia" deriva da junção do prefixo grego schizo (cortar), à palavra grega phone (voz), consistindo na separação entre um som e sua transmissão, entre um "som original" e sua reprodução e estocagem. 